\title{
Design and Architecture of a Location and Time- based Mobile-Learning System: A Case-Study for Interactive Islamic Content
}

\author{
Omar Tayan ${ }^{1,3}$, Moulay Ibrahim El-Khalil Ghembaza ${ }^{2,3}$, Khalid Al-Oufi ${ }^{1}$ \\ Dept. of Computer Engineering ${ }^{1}$, Dept. of Computer Science ${ }^{2}$, \\ College of Computer Science and Engineering, \\ IT Research Center for the Holy Quran and Its Sciences (NOOR) ${ }^{3}$, \\ Taibah University, Madinah \\ Kingdom of Saudi Arabia
}

\begin{abstract}
This paper describes a software design, architecture and process of a novel mobile-learning (m-Learning) approach based on smart-phone devices for retrieving relevant content in real-time based on the user's-location and the currenttime and presenting the content to the user in a manner that support portable learning on-the-move. Mobile-learning using Islamic content is used as a case-study of the proposed system, which can easily be adapted for other learning-content. The proposed system is highly interactive and frequently purges the host-device for details of the current user-location and currenttime (e.g. the time, day and month in the solar and the lunar calendars) before such details are used to retrieve the most relevant content. In this study, Quranic-verses, corresponding interpretations (Tafseer) and Hadith (Prophetic words or actions) relates to the online content being fetched in this application. For example, a user may be performing some travel/pilgrimage during Ramadan, in which the relevant content/teachings (based on the user's location and the current time) are presented to the user in a timely manner in order to learn the rituals of that day or location. The information fetched is then presented and displayed in an interactive user-friendly manner. A summary and comparative analysis of some related applications is presented, showing the limitations of other $\mathbf{m}$ Learning applications and demonstrating the new contribution of our architecture design. Finally, the described system allows authorized scholars to upload and report Islamic-decrees made in real-time based on findings/experience at a particular time and/or location-of-interest (e.g. the new rulings/decrees are then published online in real-time). It is anticipated that millions of end-users shall benefit from the proposed system through the benefits of fast, highly-accessible, user-friendly and relevant information retrieved online in real-time. Advantageously, the potential application and large impact of the proposed mLearning approach for use with other learning-content/courses is notable.
\end{abstract}

Keywords-Mobile-Learning; Context-Aware Notifications; Time and Location Based Reporting; Interactive-Knowledge based User-Events and Activities; Design and Architecture

\section{INTRODUCTION \& BACKGROUND}

Islamic applications for smart user-devices have become an integral part of our daily activities, particularly in times of worship and good deeds. For example, during the month of
Ramadan, or during the months of Hajj, and other rituals, it would be beneficial if such applications could be employed in an effective way for the user. Today, such Islamic applications are numerous and can be found in online stores for Apple iOS devices (App Store), Google Android devices (Play Store), Microsoft Windows 10 Mobile devices (Windows Store), and BlackBerry 10 devices (BlackBerry World). Many of those applications now include a rich set of functions such as; tools, services, and useful Islamic content, and are free of charge in most cases.

With the arrival of the blessed month of Ramadan or during other Holy events, it would be useful to utilize smartphones as support tools to assist in the remembrance of God, and assist users to perform their worship and invocations efficiently with an improved level of learning and understanding by providing relevant-knowledge based on particular user-events encountered. To achieve this goal, this paper considers the characteristics of each ritual/act-ofworship in order to retrieve the most relevant verses, supplications and invocations according to the current userenvironment. Significantly, this paper proposes an interactive Islamic application which helps to perform acts of contemplation/worship and remembrance. Moreover, the proposed application helps the user to understand the association between events, times and places, as well as the corresponding Islamic knowledge/rulings by retrieving the relevant Quranic verses, interpretations, and related Prophetic Hadiths (Prophetic Sayings) based on the user's current time and geographical location.

The proposed application supports automatic notifications as periodic reminders of supplications on a daily basis, so the user remembers to mention God at any time or place, in compliance with the verse: "And remind, for indeed, the reminder benefits the believers" [Chapter51, Verse55], and "So remember Me; I will remember you. And be grateful to Me and do not deny Me" [Chapter2, Verse152].

Essentially, this paper presents and focuses on the link between Quranic verses and Prophetic Hadiths on one hand, and a range of events and religious rituals on the other hand, which in turn are associated with a particular time or place, or with both time and place simultaneously. This paper develops 
an architecture in which the linkage between the useractivities and events is processed with all the relevant knowledge/information being presented using a smart-phone platform. Topics of events and rituals are numerous and include: holidays and worship, travel, decency, ethics, reciting Dhikr (devotional acts such as the remembrance of God), invocations, supplications, prayers and going to mosques, ablutions, fasting the month of Ramadan, acts of charity, Zakat (obligatory charity or alms-giving), Hajj and Umrah (major and minor pilgrimage), and reading/reciting the Holy Quran. Notably, such events and Islamic rituals are linked by specific times and/or geographic locations, or with both time and location conditions. Both factors play a vital role in the lifetime of Muslims.

\section{RELATED WORK}

There are hundreds of Islamic applications that are compatible with smart-phones and tablets of various kinds, some of which can be downloaded for free, while others can be purchased. Today, the most popular applications are commonly selected according to the range of features and services provided for the end-user, which also includes; builtin reminders and alerts such as relevant supplications and virtues. The degree of content-driven notifications provided by other applications is the main relationship used for comparison with this study. Hence, the following discussion provides a general description of relevant applications as well as the key highlights of any time-based or location-based notification features supported in order to compare this work with the related state-of-the-art in related $\mathrm{m}$-Learning/content-driven applications.

\section{Classification and summary of relevant and popular applications}

"Fathkrony" denoted in Arabic, which means "Remember Me" as denoted in Arabic [1], is an a smart-phone application providing remembrance-supplications (Dhikr), prayer times and a direction indicator of the Holy Kaabah (Qiblah) with an Arabic-only interface. This application contains the Holy Quran as an e-book, prayer times, a Qiblah direction indicator, daily remembrance supplications, invocations, an Islamic calendar, Ramadan calendar and a guide for pilgrims. Moreover, the application displays the prayer times and the times remaining before the next prayer commences. The user can also read the Quran and its interpretation, and provides the ability to search for specific verses and share it with friends via Facebook and Twitter. Supplication reminders are also provided after each prayer. What distinguishes "RememberMe" from other applications is the possibility of scheduling the recitation of the Holy Quran, where you can choose the number of days to complete the recitation of the Quran. The application also calculates the daily Quran recitation progress. Some of the relevant notification features in this application includes: notifications of prayer Athans (call-to-prayer) and notifications for morning and evening supplications. However, some limitations in the application include; an Arabic-only interface, inaccurate Qiblah direction indicator, and no means for listening to the recitation of the Quran or supplications.

"AlMosally" [2] is a smart-phone application that searches for nearby mosques and provides remembrance-supplications.
This application is freely available for iOS and Android devices and provides a tool that searches for nearby mosques. A map-based interface is also used to find the most accurate routes. The user can also access a number of other functions, including: prayer time alerts, Quranic supplications, fasting supplications, the direction of the Qiblah from any location, and finally, the Hijri (Islamic) calendar. One of the main advantages that is unique to this application is the "silent mode during prayer" times feature, and the feature to "show the nearest mosque" using the GPS functionality. Similar to [1], this application had provided notifications for Athan times and morning/evening supplications. The drawbacks found in this application include; lack of support for the supplications feature (limited for some functionality), and that there is no possibility of listening to the supplications or the recitation of the Quran.

"Mutawef" [3] is an Arabic-only smart-phone application dedicated for assisting pilgrims with the rituals of Hajj and Umrah (e.g. the major and minor pilgrimage to the Kaabah/House-of-God). This application provides a complete guide for pilgrims visiting the House of God. Essentially, it informs users of important places to visit as part of the rituals using live pictures and maps for ease and convenience. It provides the user with supplications used during Hajj and displays descriptions of Hajj and Umrah, with details of common mistakes to avoid.

Some of the main features of this application include:

- "Guide me" service: this feature protects the pilgrim from straying away from his residence in Makkah or Mina/Arafat through the use of maps and guidelines.

"Al-Haram" guide: is an intelligent guide for all services and locations within the perimeter of Al-Kaabah, and includes; the gates of Al-Kaabah, elevators, escalators, places of ablutions, toilets, security-lockers, health centers, the Red Crescent, places of prayer for disabled people, etc.

"Audio guide": a free voice service through which users listen to an explanation of all the rituals of Hajj in various languages provided by the Ministry of Islamic Affairs in Saudi Arabia.

- "Advise me": a free voice service through which users can inquire with Islamic scholars concerning Islamic rulings provided by the General Secretariat of the Islamic awareness in Saudi Arabia.

Only very limited support for content notifications was found in this application, and is only available in Arabic. In addition, the settings options are only provided for one notification feature.

"Athan Pro Prayer Times" [4] is a smart-phone application that provides prayer timings, Athan and a Qiblahdirection indicator. This application is used by thousands of users worldwide. It provides user-location prayer times and many other useful features such as the Holy Quran recitation mode (through a service provided by the Quran Pro Application [8] by the same developer), remembrancesupplications, and a calendar of Islamic holidays. Additionally, the application calculates the timings of prayers with good accuracy. It provides multiple calculation methods 
for worldwide prayer-times that include: 1. Umm Al Qura University, 2. Muslim World League, 3. University of Islamic Sciences of Karachi, 4. Egyptian General Authority of Survey, 5. Islamic Union of North America. Some notification functionality was provided in terms of Athan alerts and messages that relate the Hadith of the day. The main drawback of this application is that many advertisements appear within every service, and removing the advertisements is only available with a service cost.

"Muslim Pro - Prayer Times, Azan, Quran \& Qibla" [5] is a smart-phone application providing Athan, Qiblahdirection, prayer timings and Holy Quran recitation. This free application is used by more than 25 million users throughout the world. It uses an accurate timing calculation method for the prayer timings and Athan based on the user-location. Muslim Pro also contains the Holy Quran text with audio recitations and translations. Additionally, it provides a Qiblah direction indicator and an Islamic Hijri calendar. The mapservice identifies locations of Halal restaurants, and mosques. Finally, the application and Quran-text are fully interpreted in the following languages: Bahasa Indonesia, Bahasa Melayu, Deutsch, English, Spanish, French, Italian, Hollands, Portugal, Turkish, Arabic, Urdu, Russian, Simplified Chinese, Japanese, and Thai Language. Notification features were evident in the form of prayer-time alerts and verse-of-the day alerts. On the other hand, the Qiblah direction indicator is inaccurate and not straightforward to use. Additionally, many advertisements appear within the application, and removing them is only available with a service cost. Additional voices for the audio Quran and the Athan are only available with a service cost.

"AlSalam" [6] is a free and comprehensive Islamic application that provides a library of Islamic content and rituals. AlSalam provides prayer times, Quran, Qiblah direction and Athan functionality. Some of the more notable features of this application includes: a categorized library of knowledge, user-location prayer-times, Qiblah direction, a calendar convertor, a search-engine and multiple-language Quran translations. In this application, only one notification feature was found in the case of prayer-time alarms. It was noted, however, that the Qiblah direction indicator was inaccurate and its use was not straightforward. Many advertisements appear in the application, and removing them is only available with a service cost. Finally, the settings options in this application are very limited.

"Athan - Prayer times, Qibla and Mosques finder" [7], is a smart-phone application featuring Athan, prayer-timings and Qiblah direction. This free application is used by over one million users according to the latest download statistics [7]. This well-designed application is available for Android and iOS devices. However, this application has many interrupting advertisements, and removing them is only available with a service cost. Notifications were only found for prayer alarms. The Qiblah direction indicator is inaccurate and its use is not straightforward. Finally, the application is a limited version and extra features, such as; complete Quran translations and Athan voices are only available with an extra cost.

"Quran Pro" [8], is a smart-phone application with an English-only interface that features; Quran-text with Othmanic font and 20 language translations, Arabic Tafseer, bookmarks, supplications, daily verse of the day notifications and Friday's reminder. However, the Athan function invokes another application provided by the same developer.

"Golden Quran" [9], provides an Othmanic font for the Holy Quran and provides audio recitations in an interactive way. The application interacts with the verse and provides many features about interpretations, Tajweed (rules governing pronunciation of recitation), Morphology, and other Quranic sciences. In addition, other features are provided that includes: prayer times, Qiblah direction indicator and a search engine for Quranic verses and chapters. The application provides advanced Quranic services and a settings option. Notifications are provided for invocations, reminder to read the Quran, and others, but some notifications do not work. Finally, the Qiblah direction indicator is inaccurate and not straightforward to use.

"Muslim Mate" [10], is a comprehensive Islamic mobile application that provides; prayer-times, a Qiblah direction indicator, a Quran search engine, multilingual phonetic transliterations, translations \& recitations, and a locator for nearby places of interest. However, this application is only available for iOS devices. Finally, notifications are mainly provided for Athan/prayer times and calendar/events only. The application provides advanced setting options, however, the settings options are scattered in the application under each service. The application only displays the Quran verse-byverse rather than page-by-page. Many adverts appear during the use of the application, with can only be removed with a service cost.

The next section explains the analysis used for comparing the other related efforts with this work. Section IV describes the proposed design and architecture.

\section{DISCUSSION AND ANALYSIS}

Related studies focusing on mobile applications had proposed various feature-analysis criterion; and based on those criteria, had presented comparisons, evaluations and assessments concerning the use of such applications, as well proposing requirements guidelines in order to help users select between a large range of applications. For instance, the work in [11] was based on the user friendliness, completeness, and quality of use as the main assessment criteria. On the other hand, the work in [12] had considered the perceived usefulness, content quality, layout/graphic design, and application's ease of use as their main criteria.

The criterion used in this study consists of four categories and fourteen subcategories used in the requirements analysis when comparing between the related applications. Table 1 shows the categories and subcategories used and presents a summary of the main features of the most relevant smartphone applications $[1-10]$. The criteria selection was largely tied to the nature of the application, its content and it main goals. The first category (Content) is related to the content, which is a very sensitive point when it comes to the Holy Quran. For instance, the Othmanic text font for the Quran is widely used for print back copies and could be a requirement of many users of smart-phone applications. Secondly, the complete Quran text in such applications is desirable since the 
Quran is considered as the companion of its users in all times and places. According to Table 1, we note the absence of those two criteria in two of the ten selected applications as samples for the study, while [4] uses an external application [8] (from the same developer) to fulfill this requirement. Requirements 3 and 4 are considered as important in terms of access to information within the application; and in two of the ten selected applications there is no search feature for Quranic chapters that allow the user to navigate to the chapters and verses directly. It is noted that in five of the ten examined applications, there is no search feature for the Quranic chapter names or the Quranic verses, while in [10] this feature is available with a service cost. Hence, this offers researchers and developers an opportunity for further development in this area.

The second category of requirements (Multimedia and Notifications) is considered essential for educational purposes, and allows users of the application to improve recitation skills by listening to audio recitations of the Quranic verses. This criteria is only present in four out of ten of the selected applications. As one of the objectives of this study was to compare alerts/notifications with related applications, it was noted that notification features were found in some of those other applications to various extents and with their limitations. For instance, some applications had used voice and text for alerts, while others used text only as in [3 and 4]. Concerning the offline access to the text and audio content, it was found that five of ten applications had provided support for this feature.

In the third category of requirements (Translation and Interpretation), we find that many of the applications being examined had no support for providing the interpretation of the Quranic verses in any language, while in [10] this feature is available with a service cost. The interpretation of the Quran is considered necessary for users to understand the meanings and purposes of the verses. Additionally, some applications do not support multiple languages in the userinterface, which is considered as a major limitation since the proportion of non-Arab users is much higher than the proportion of Arab users.

The last category of requirements (Implementation and Distinguished Features) concerns the applications themselves in terms of usage costs, periodic updating, technical support, follow-up development updates and the availability of the application in different mobile operating systems. Most of the applications considered here had addressed those requirements [2 - 8, and 10].

A number of relevant studies were found that describe efforts related to the latest developments in Quran applications using mobile technology [13], whilst the quality-assurance factors and security concerns for such applications were highlighted in [14] and [15 - 16], respectively. Readers interested in solutions for dealing with sensitive digital image content found in many content-based applications are referred to the discussions made in [17 - 19].

\section{SYSTEM DESIGN AND ARCHITECTURE}

The proposed system design and architecture comprises of two main parts:

1) The monitoring and display at the user-end, and;

2) The content-search and retrieval algorithm at the backend server.

The monitoring and display part at the user's side is where the system gathers local-time and current-location data, which is sent to the backend servers using online communications before displaying the retrieved content. Figure 1 illustrates the concept of monitoring and content-display at the user-end.

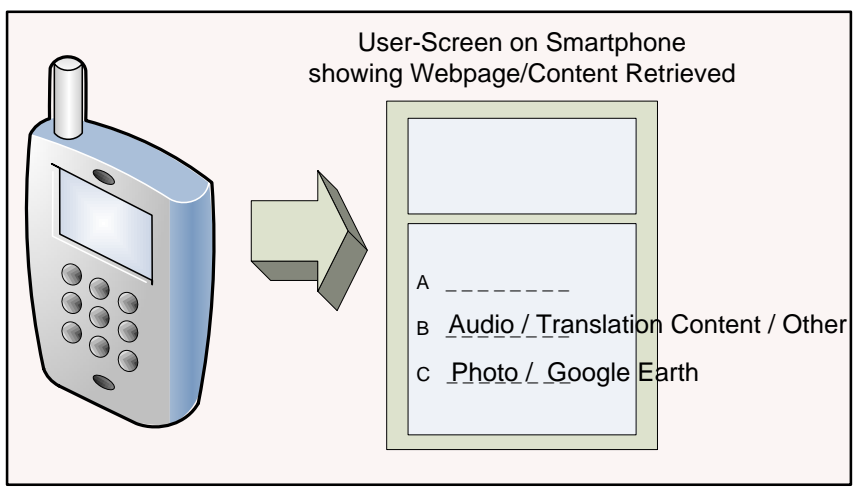

Fig. 1. Conceptualization of User-End Content Monitoring and Display 
TABLE I. COMPARATIVE ANALYSIS OF RELEVANT CURRENT RELATED APPLICATIONS

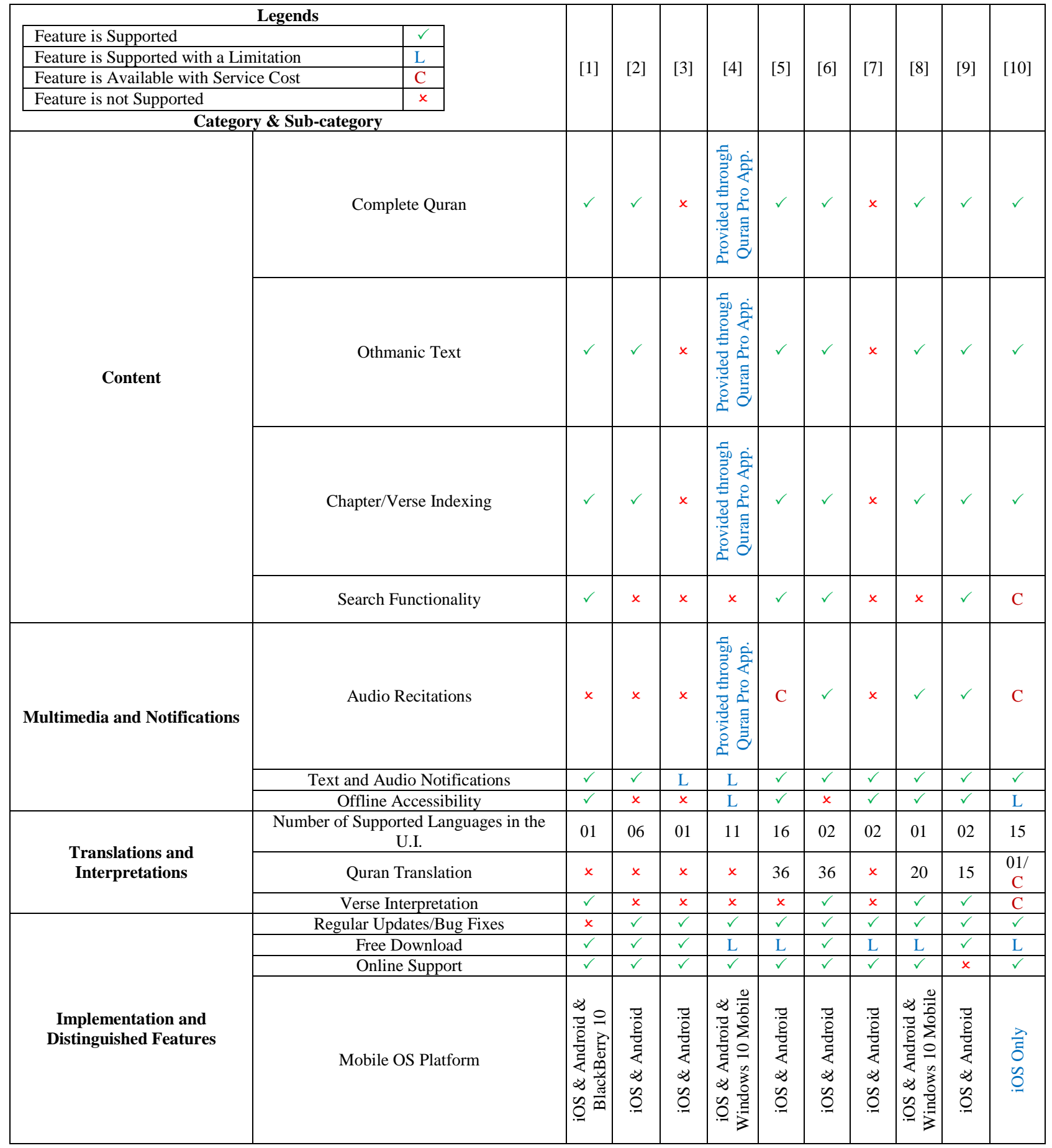

At the backend server side, the retrieved time and location data for each user is then processed by searching through a database of Quranic verses and Hadith, and retrieving the most appropriate verses and Hadith (if any) for that particular user time and location. Data retrieval and processing at the backend can be decomposed into three essential components, including: converting between Gregorian and Islamic calendars as per notification requirements, determining prayer-time calculations based on the user-location, and determining the user's immediate environment. In the first instance, calendar conversions are typically achieved in the implementation by employing integrated API functionality within the library functions. The user's immediate location and surroundings are obtained using the Google Map Web Service (GMWS) [20], while the location-based prayer-time calculations were determined using the GMWS data as input to the Islamic-Finder service for selecting the desired calculation algorithm provided through their web-service [21]. Finally, the retrieved data is transmitted to the user's device for display and/or playback. The proposed system framework also supports uploading Fatwas into the database by 
authorized Islamic scholars in real-time, and consequent retrieval and display of Fatwas at the user-end (where applicable) along with the other content retrieved. The principle system architecture diagram, showing the main functional components at the user-end and backend server is illustrated in Figure 2.

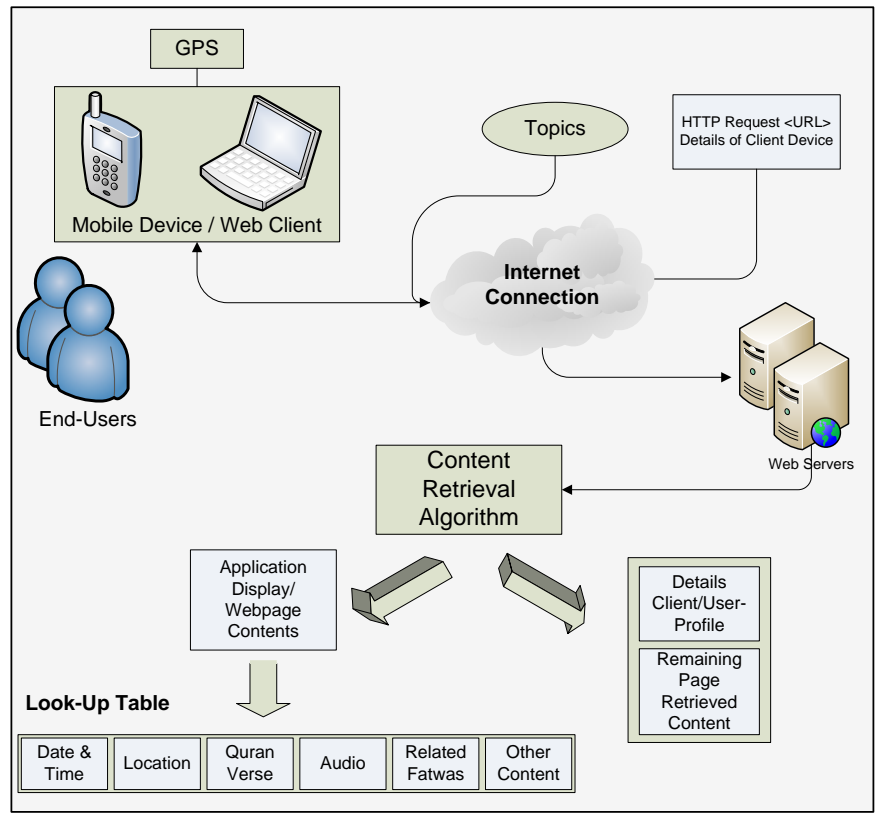

Fig. 2. System Architecture Diagram

\section{INITIAL RESULTS}

This section presents some results that report on initial tests performed on the developed application. Table 2 presents the results related to two test cases. The first case relates to a time-based condition only (e.g. at Asr prayer time), while the second case relates to a time and location based condition (e.g. at Adhan times and at a transport station).

\section{TABLE II. SAMPLE RESULTS OF NOTIFICATIONS RETRIEVED}

\begin{tabular}{|c|c|c|}
\hline \multicolumn{2}{|c|}{ User-Events } & \multirow{2}{*}{ Corresponding Notification Verse(s) } \\
\hline Time & Place/ Location & \\
\hline $\begin{array}{l}\text { Asr prayer } \\
\text { Time }\end{array}$ & $\begin{array}{l}\text { Anywhere } \\
\text { (prayer times } \\
\text { depends on user- } \\
\text { location) }\end{array}$ & $\begin{array}{l}\text { Maintain with care the [obligatory] } \\
\text { prayers and [in particular] the middle } \\
\text { prayer and stand before Allah, devoutly } \\
\text { obedient [Al-Baqarah (The Cow), 283]. }\end{array}$ \\
\hline $\begin{array}{l}\text { At Every } \\
\text { Adhan }\end{array}$ & $\begin{array}{l}\text { At any } \\
\text { transportation } \\
\text { station (train, } \\
\text { bus, airport) OR } \\
\text { while travelling }\end{array}$ & $\begin{array}{l}\text { And when you travel throughout the } \\
\text { land, there is no blame upon you for } \\
\text { shortening the prayer, [especially] if you } \\
\text { fear that those who disbelieve may } \\
\text { disrupt [or attack] you. Indeed, the } \\
\text { disbelievers are ever to you a clear } \\
\text { enemy [An-Nisa' (The Women), 101]. }\end{array}$ \\
\hline
\end{tabular}

\section{CONCLUSIONS}

The location and time based content retrieval system presented in this work provided an effective and practical approach for users to learn about relevant content at any time, while on the move. In this case-study, time-based and location-based Quran verses and Hadiths related to user's daily lifestyles (including events and rituals) were presented in an interactive way using mobile technology. The main novelty in this work was found in the idea, its application and system framework for use with mobile technology, which was not found in the current literature or in existing mobile applications. The proposed framework executes a number of functional stages at the user-side and backend server-side, and could be easily adapted and employed for use in many other related m-Learning application domains. Finally, some initial results were presented to demonstrate the functionality of the proposed architecture using several examples as a proof-ofconcept of the described design and architecture.

\section{REFERENCES}

[1] "Fadhkroni". Available at http://moubadarah.bankalbilad.com/fathkrony. Last Accessed on $10^{\text {th }}$ December 2016.

[2] "AlMosally". Available at https://www.facebook.com/almosaly. Last Accessed on $10^{\text {th }}$ December 2016.

[3] "Mutawef". Available at http://www.mutawef.com. Last Accessed on $10^{\text {th }}$ December 2016.

[4] "Athan Pro Prayer times". Available at http://islam.quanticapps.com. Last Accessed on $1^{\text {st }}$ February 2017.

[5] "Muslim Pro - Prayer Times, Azan, Quran \& Qibla", Available at http://www.muslimpro.com. Last Accessed on 10 ${ }^{\text {th }}$ December 2016.

[6] "AlSalam". Available at https://www.facebook.com/Rommanapps. Last Accessed on $1^{\text {st }}$ February 2017.

[7] "Athan - Prayer times, Qibla and Mosques finder". Available at https://www.islamicfinder.org. Last Accessed on $1^{\text {st }}$ February 2017.

[8] "Quran Pro". Available at http://islam.quanticapps.com. Last Accessed on $1^{\text {st }}$ February 2017.

[9] "Golden Quran". Available at http://www.blogofapps.com/best-islamicapps-for-iphone. Last Accessed on $1^{\text {st }}$ February 2017.

[10] "Muslim Mate". Available at http://www.muslimmateapp.com. Last Accessed on $1^{\text {st }}$ February 2017.

[11] K. Z. Zamli and al., "Feature Analysis of Android based Holy Quran Applications", 2013 Taibah University International Conference on Advances in Information Technology for the Holy Quran and Its Sciences.

[12] M. Alqahtani, A. Fayyoumi, "Mobile Application Development for Quran Verse Recognition and Interpretations", International Journal of Interactive Mobile Technologies, Vol. 9, No 1, 2015.

[13] M. Zakariah, M.K. Khan, O. Tayan, K. Saleh, "Digital Quran Computing: Review, Classification, and Trend Analysis", Arabian Journal for Science and Engineering - February 2017, DOI: 10.1007/s13369-017-2415-4

[14] Hafidh Alsamarrai; Omar Tayan; Maysam Abbod; Yasser M. Alginahi, "Requirements Assessment for Organizations, Users, Software Developers, and Funders for the Propagation of the Holy Quran and Its Sciences", Taibah University International Conference on Advances in Information Technology for the Holy Quran and Its Sciences, Madinah, KSA, 22-25 Dec 2013.

[15] O.Tayan, "Concepts and Tools for Protecting Sensitive Data in the IT Industry: A Review of Trends, Challenges and Mechanisms for DataProtection", International Journal of Advanced Computer Science and Applications 8(2) - March 2017.

[16] O. Tayan, Y. Alginahi, "A review of recent advances on multimedia watermarking security and design implications for digital Quran computing", International Symposium on Biometrics and Security Technologies (ISBAST), 2014, At Kualal Lumpur, Malaysia, DOI: 10.1109/ISBAST.2014.7013139.

[17] L. Laouamer, O. Tayan, "An Efficient and Robust Hybrid Watermarking Scheme for Text-Images", International Journal of Network Security 18(6):1152-1158 - November 2016.

[18] L. Laouamer, O. Tayan, "A Semi-Blind Robust DCT Watermarking Approach for Sensitive Text Images", Arabian Journal for Science and Engineering 40(4):1097-1109 - April 2015, DOI: 10.1007/s13369-015$1596-y$. 
[19] L. Laouamer, O. Tayan, "An enhanced SVD technique for authentication and protection of text-images using a case study on digital Quran content with sensitivity constraints", Life Science Journal 2013;10(2).
[20] Google Places Web-API [Online] Available at https://developers.google.com/places/web-service/supported_types. Last Accessed on $10^{\text {th }}$ December 2016.

[21] Islamic-Finder Prayer Times Web-Service [Online] Available at https://www.islamicfinder.org/world. Last Accessed on $10^{\text {th }}$ December 2016. 